\title{
INFLUÊNCIA DO ATAQUE POR ÁCIDO SULFÚRICO NA VARIAÇÃO DIMENSIONAL DE CORPOS DE PROVA DE ARGAMASSA DE DIFERENTES TIPOS DE CIMENTOS
}

\author{
Influence of the sulfuric acid attack on the dimensional variation of \\ samples of different types of cement
}

\author{
Marion Scheffer de Andrade Silva ${ }^{1}$, Jayson Pereira Godinho ${ }^{2}$, Adriano Mohr Bonatto ${ }^{3}$, \\ Juliana Janowski Zandoná ${ }^{4}$, Luis Cesar Siqueira de Luca ${ }^{5}$, Marcelo Henrique Farias de Medeiros ${ }^{6}$
}

Recebido em 07 de abril de 2017; aceito em 28 de setembro de 2017; disponível on-line em 07 de novembro de 2017.

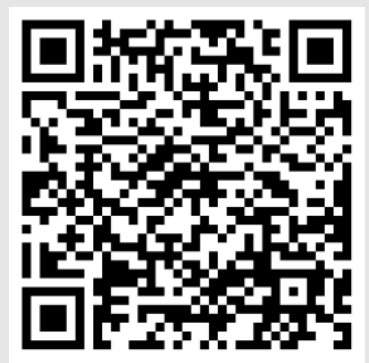

PALAVRAS CHAVE:

Ataque ácido;

Ataque por sulfatos;

Variação dimensional;

Variação de pH;

Expansão.

\section{KEYWORDS:}

Acid attack;

Sulphate attack;

Dimensional variation;

pH variation;

Expansion.

* Contato com os autores:

1e-mail: mari125@gmail.com (M. S. A. Silva)

Eng. Civil, Mestranda em Engenharia de Construção Civil (PPGECC), Universidade Federal do Paraná (UFPR), câmpus Curitiba.

2e-mail: jayson.godinho.eng@gmail.com (J.P. Godinho )

Eng. Ambiental e de Segurança do Trabalho, Doutorando em Engenharia de Construção Civil (PPGECC), Universidade Federal do

Paraná (UFPR), câmpus Curitiba.

${ }^{3}$ e-mail: adrianombonatto@yahoo.com.br ( A. M. Bonatto )

Eng. Civil, Especialista em Patologia nas Obras Civis (Instituto IDD), Especialista de OAEs na Rumo Logística.

${ }^{4}$ e-mail: juliana.zandona@outlook.com (J. J. Zandoná )

Eng. Civil, Especialista em Patologia nas Obras Civis (Instituto IDD), Responsável técnica na Construtora e Incorporadora Laguna.

${ }^{5}$ e-mail: deluca@idd.com.br ( L.C. S. de Luca )

Eng. Civil, Mestre em Eng. Civil (UFSC), Diretor executivo e professor no Instituto IDD, câmpus Curitiba.

${ }^{6}$ e-mail: marcelo.ufpr@gmail.com (M. H. F. de Medeiros )

Eng. Civil, Doutor em Eng. Civil (USP), Docente da Universidade Federal do Paraná (UFPR), câmpus Curitiba. 


\section{INTRODUÇÃO}

A degradação de estruturas de concreto pelos íons sulfato pode ocorrer pelo contato entre o concreto e solos que contenham sulfato, ou em águas subterrâneas que possuem em sua concentração sulfato de magnésio, sódio e potássio. Além disso, a estrutura pode ter degradação se entrar em contato com sulfato de amônia que pode estar presente em terras e águas agrícolas, ácido sulfúrico liberado por indústrias, ou ácido sulfúrico biogênico presente nos esgotos domésticos (redes coletoras e ETEs), poços de mineração, rios e pântanos que tenham matéria orgânica em processo de decomposição (MEHTA; MONTEIRO, 2014).

A diferença entre as soluções de exposição é a severidade do ataque resultante, sendo, por exemplo, o ácido sulfúrico mais severo do que o sulfato de magnésio e esse mais severo do que o sulfato de sódio (TORII; KAWAMURA, 1994).

O ataque ácido às estruturas do sistema de tratamento de esgoto envolve diversos fatores, tais como a presença de gás carbônico e sulfeto de hidrogênio $\left(\mathrm{H}_{2} \mathrm{~S}\right)$, que causam a redução do $\mathrm{pH}$ do concreto, na presença de bactérias, que utilizam compostos do esgoto para produzir ácido sulfúrico biogênico (OKABE et al., 2007). Outros fatores que influenciam a degradação das estruturas são a umidade do ar na superfície não submersa das estruturas e a temperatura do gás sulfeto de hidrogênio, que podem acelerar o processo de degradação (JIANG et al., 2015). O conhecimento de fatores e processos responsáveis pela deterioração facilitaria a estimativa, o controle de taxas de deterioração e a elaboração de estratégias de mitigação do ataque, que muitas vezes não são tão eficazes quanto o esperado, apesar dos substanciais custos econômicos envolvidos (JOSEPH et al., 2012).

Para exemplificar a severidade da deterioração de estruturas submetidas ao tratamento de esgoto, pode ser citado um experimento realizado na Austrália, no qual estimou-se que a taxa de deterioração foi equivalente a $12 \mathrm{~mm} / \mathrm{ano}$ de espessura de concreto. A amostra utilizada foi cortada de tubos de esgoto de concreto recém-fabricado e o ambiente de exposição foi um sistema de esgoto com altas concentrações de $\mathrm{H}_{2} \mathrm{~S}$ localizado em Perth, Austrália (WELLS; MELCHERS, 2014). Considerando que a taxa de deterioração registrada no experimento foi de $12 \mathrm{~mm} / \mathrm{ano}$ e levando em conta que a NBR 6118 (ABNT, 2014) especifica que o cobrimento das estruturas de concreto em ambientes agressivos seja de $45 \mathrm{~mm}$ a $50 \mathrm{~mm}$ para concreto armado, ao final de quatro anos uma armadura poderia estar despassivada e suscetível à corrosão.

Outro exemplo de deterioração precoce de estruturas pode ser verificado nas investigações realizadas em sistemas de tratamento de esgoto na Áustria, onde a taxa de deterioração do concreto foi acima de $10 \mathrm{~mm} /$ ano. Isso causou danos a grandes regiões do sistema de tratamento de esgoto, que foram severamente deteriorados em apenas nove anos de uso. A degradação ocorreu apesar de terem sido usados cimentos resistentes a sulfatos, com adição de cinzas volantes, relação água/cimento de 0,35 e cimento com baixo teor de $\mathrm{C}_{3} \mathrm{~A}$ (GRENGG et al. 2015).

Em dados de sistemas de tratamento brasileiros apresentados por Hoppe Filho et al. (2014), que fizeram um estudo com testemunho extraído de uma Estação de Tratamento de Esgoto (ETE), em Curitiba-PR, foi possível verificar um avanço nos parâmetros normativos nos últimos quinze anos. O projeto da ETE estudada foi elaborado em 1995, sendo que, na época, a NBR 6118 - Projetos de estruturas de concreto armado - Procedimento, especificava que o concreto deveria ter resistência característica à compressão de $15 \mathrm{MPa}$ e 1,5 cm de cobrimento das armaduras. No projeto da ETE estudada, a especificação para fck do concreto foi de $22 \mathrm{MPa}$ e o cobrimento examinado no local foi de $2,5 \mathrm{~cm}$, superior aos valores previstos pela norma vigente e, ainda assim, foram encontradas evidências de severas manifestações de ataque por sulfatos ao concreto, em pouco mais de 15 anos em operação. 
A NBR 6118 (ABNT, 2014) não especifica os materiais para serem aplicados a estas estruturas sujeitas a ataque por ácido sulfúrico ou ácido sulfúrico biogênico, em particular. As especificações apenas remetem a algumas propriedades dos materiais utilizando o quesito de classificação por agressividade ambiental e, então, delimitam a resistência à compressão mínima, relação água/cimento máxima e o cobrimento mínimo das armaduras. Em outra parte da NBR 6118 (ABNT, 2014) é especificado que para prevenir a expansão por sulfatos, deve-se utilizar um cimento resistente a sulfatos, sendo este regulamentado pela NBR 5737 (ABNT, 1992) e é especificado ainda o ensaio da NBR 13583 (ABNT, 2014) para testar a expansão em ambiente com sulfato de sódio. As normas técnicas não especificam as características deste tipo de estrutura quanto ao tipo de agregado que deve ser utilizado, tipo de impermeabilização ou até mesmo outras especificações para essas estruturas em particular.

Visto que há lacunas quanto às especificações técnicas de materiais para esse tipo de estrutura, é importante que os estudos nessa área sejam realizados com o intuito de entender os processos de degradação neste tipo de estrutura e, assim, gerar conhecimento científico e técnico acerca dos materiais que atendam mais satisfatoriamente as características de vida útil nestes microclimas.

Neste contexto, a presente pesquisa teve o objetivo de avaliar a influência do tipo de cimento na variação dimensional de corpos de prova de argamassa expostos ao ataque por soluções agressivas de ácido sulfúrico.

\section{MATERIAL E MÉTODOS}

\subsection{PROGRAMA EXPERIMENTAL}

O programa experimental consistiu na moldagem de corpos de prova de argamassa prismáticos de 2,5 × 2,5 x 28,5 cm, com diferentes tipos de cimento (CP II Z, CP IV-32 RS e CPV-ARI). Os corpos de prova foram expostos a soluções agressivas de sulfato de sódio e ácido sulfúrico e foram realizadas medições da expansão ao longo do tempo e análises visuais dos corpos de prova (cp) nas idades de medição. As medições de expansão foram relacionadas com a variação de massa dos corpos de prova ao longo do tempo.

Para a realização da análise estatística dos resultados, uma vez que o ensaio de variação dimensional com ácido sulfúrico não é normatizado, foram moldados dois corpos de prova a mais do que os quatro especificados pela NBR 13583 (ABNT, 2014). No entanto, após a moldagem houve a quebra de três corpos de prova de CP IV-32 RS, desta maneira, foram utilizados cinco corpos de prova por série para este tipo de cimento, enquanto para os demais a quantidade de seis corpos de prova foi mantida. A quantidade de corpos de prova utilizados está descrita na Tabela 1.

A sistematização das etapas do trabalho foi feita conforme descrito na Figura 1.

TABELA 1: Quantidade de corpos de prova.

\begin{tabular}{ccccc}
\hline Cimento & Água & Ácido sulfúrico & Sulfato de Sódio & Total \\
\hline CP II Z & 6 & 6 & 6 & 18 \\
CP IV-32 RS & 5 & 5 & 5 & 15 \\
CP V & 6 & 6 & 6 & 18 \\
\hline & Total & $\mathbf{5 1}$
\end{tabular}




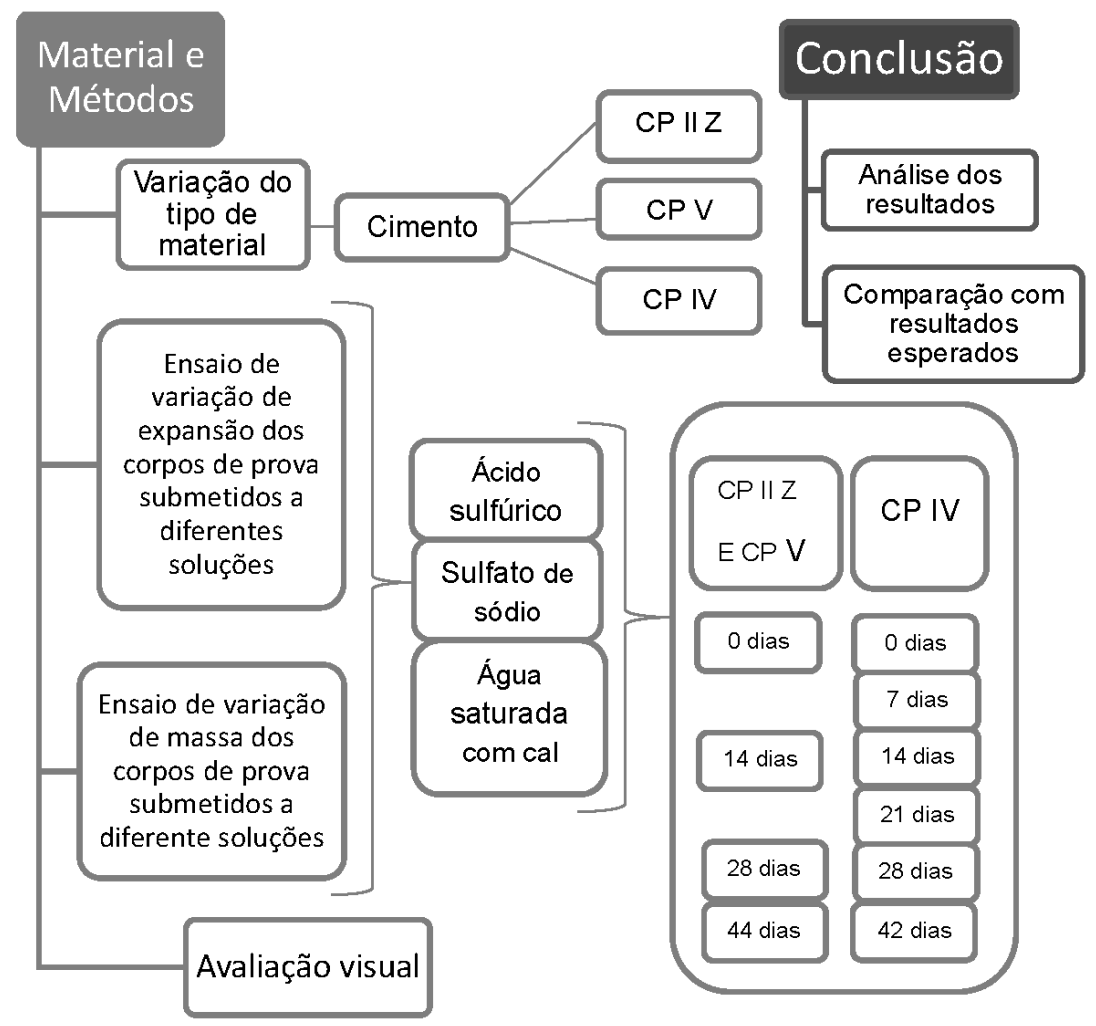

FIGURA 1: Sistematização do programa, incluindo o programa experimental e sua conclusão. FONTE: Autoria própria.

Pelo fato da atividade pozolânica se estender nas idades iniciais de concretos e argamassas, decidiu-se estender também o tempo de cura dos corpos de prova deste trabalho em comparação ao tempo previsto em norma, para que as reações pozolânicas fossem mínimas durante o período de exposição. Se o corpo de prova fosse submetido à solução agressiva após 48 $h$, conforme previsto em norma, ao mesmo tempo em que as reações pozolânicas estariam acontecendo, este estaria sendo atacado.

Deste modo, o período de cura adotado foi de 104 dias para todos os corpos de prova expostos à solução de sulfato de sódio e água saturada com cal e de 155 dias para os corpos de prova expostos à solução de ácido sulfúrico com concentração de $1 \%$.

Os ensaios de variação dimensional tiveram como base a metodologia proposta pela NBR 13583 (ABNT, 2014), apesar de a norma não preconizar o uso de solução de ácido sulfúrico.

Como a solução de ácido sulfúrico é muito agressiva e não há norma para este ensaio, o tempo para primeira medição foi adaptado para 7 dias para garantir que os dados sejam melhor interpretados, já que os corpos de prova apresentam ataque visível desde os primeiros dias de imersão. Como o ataque em solução de ácido sulfúrico é acelerado, foi feita uma medição intermediária entre as datas previstas para medição na norma de 14 e 28 dias e foi feita uma medição aos 21 dias de idade.

A norma prevê a medição dos corpos de prova com 42 dias de imersão em solução agressiva, porém neste trabalho os corpos de prova expostos à solução de sulfato de sódio foram medidos aos 51 dias, pois não houve possibilidade de realizar as medições na data programada, e os corpos de prova imersos em solução de ácido sulfúrico precisaram ser medidos aos 44 dias.

Passado o prazo previsto em norma, foram feitas medições para os corpos de prova imersos em solução de sulfato de sódio nas idades mostradas Tabela 2. 
TABELA 2: Idades de medição dos corpos de prova.

\begin{tabular}{ccccccc} 
Solução & $\mathbf{7}$ dias & $\begin{array}{c}14 \\
\text { dias }\end{array}$ & $\begin{array}{c}\mathbf{2 1} \\
\text { dias }\end{array}$ & $\begin{array}{c}\mathbf{2 8} \\
\text { dias }\end{array}$ & $\begin{array}{c}\mathbf{4 4} \\
\text { dias }\end{array}$ & $\begin{array}{c}\mathbf{5 1} \\
\text { dias }\end{array}$ \\
\hline $\begin{array}{c}\text { Sulfato de } \\
\text { sódio }\end{array}$ & - & SIM & - & SIM & - & SIM \\
$\begin{array}{c}\text { Ácido } \\
\text { sulfúrico }\end{array}$ & SIM & SIM & SIM & SIM & SIM & - \\
\hline & & & & & FONTE: Autoria Própria.
\end{tabular}

Foram feitas as medições em todas as idades para a solução de água saturada com cal para que fosse possível calcular a variação resultante.

\subsection{CARACTERIZAÇÃO DOS MATERIAIS}

Tendo em vista o objetivo da pesquisa, foram adotados para a realização dos ensaios três tipos de cimento diferentes disponíveis no mercado nacional. Desta forma foi possível comparar o desempenho de cada tipo de cimento quando exposto à soluções agressivas.

\subsubsection{Cimento}

Os tipos de cimento escolhidos foram o CP IV-32 RS, que possui a maior quantidade de material pozolânico dentre os cimentos selecionados (de 15 a $50 \%$ ), o CP II Z que também possui em sua composição material pozolânico, porém em um percentual mais baixo (de 6 a 14\%) e o CP V ARI, que tem uma moagem mais fina e tem a característica de atingir elevada resistência inicial.

\subsubsection{Agregado Miúdo}

O agregado miúdo utilizado foi areia média natural peneirada, da região metropolitana de Curitiba, que foi seca a 105 $\mathrm{C}$ até apresentar constância de massa.

A caracterização do agregado miúdo foi obtida de acordo com as características preconizadas pela NBR 7211 (ABNT, 2009) com a apresentação dos parâmetros apresentados na Tabela 3, tais como, massa específica $\left(\mathrm{g}_{\mathrm{cm}} \mathrm{cm}^{-3}\right)$, massa unitária $\left(\mathrm{g} . \mathrm{cm}^{-3}\right)$, módulo de finura, teor de material pulverulento (\%).

\section{TABELA 3: Caracterização do agregado miúdo (areia natural).}

\begin{tabular}{cc} 
Areia natural & Norma Brasileira \\
\hline Massa específica $\left(\mathrm{g} / \mathrm{cm}^{3}\right)$ & NBR NM 52 (ABNT, 2003) \\
\hline Massa unitária $\left(\mathrm{g} / \mathrm{cm}^{3}\right)$ & NBR 7251 (ABNT, 1982) \\
\hline Módulo de finura & NBR NM 248 (ABNT, 2003) \\
\hline Teor de material pulverulento (\%) & NM 46 (ABNT, 2003) \\
\hline Composição granulométrica & NBR NM 248 (ABNT, 2003) \\
\hline
\end{tabular}




\subsection{ENSAIOS DE VARIAÇÃO DIMENSIONAL}

\subsubsection{Realização do ensaio}

O traço utilizado para os ensaios foi 1:3,2:0,6. Os moldes foram prismáticos de $25 \times 25$ x $285 \mathrm{~mm}$, conforme previsto na NBR 1358 (ABNT, 2014). Os pinos de aço inoxidável foram ajustados antes do preenchimento dos moldes.

Após a moldagem dos corpos de prova, os mesmos foram deixados em cura antes de serem colocados em imersão. Após a imersão, os corpos de prova foram colocados em recipientes montados com tubos de PVC de $150 \mathrm{~mm}$, como CAP também de PVC para que fossem deixados imersos na solução e aquecidos em banho-maria para que a temperatura fosse mantida.

Após isso, os corpos de prova foram colocados em caixas de plástico, separados por amostra de tipo de cimento e tipo de solução e colocados na estufa a temperatura constante de 40 ㄷ. Como apoio para os corpos de prova, para que os mesmos não tocassem o fundo, foram utilizadas canaletas do tipo "sistema X", que são comumente utilizadas para realizar instalação elétrica, para apoiar as duas extremidades do corpo de prova.

Antes da colocação da tampa do recipiente, o mesmo era coberto com papel filme de plástico para evitar que a solução evaporasse com o calor.

A NBR 13583 (ABNT, 2014) preconiza que as barras sejam medidas com um extensômetro nas idades de 14, 28 e 42 dias. Neste trabalho foi feita a medição aos 7 dias já que o ácido sulfúrico é mais agressivo e começaria e danificar a peça mais rápido que o sulfato de sódio e ultrapassados os 42 dias para melhorar os dados estatísticos.

\subsubsection{Análise visual}

Conforme descrito na NBR 13583 (ABNT, 2014), deve-se analisar nas idades de medição o aspecto visual das barras, registrando toda e qualquer anomalia apresentada, tais como: fissuração das barras, o tamanho e intensidade das fissuras, desagregação parcial, total ou empenamento das barras, alterações na temperatura de cura ao longo do ensaio, evaporação da água de imersão, com necessidade de complementação, impossibilidade de leitura com o extensômetro e, portanto, emprego de paquímetro ou outro instrumento de medida.

Desta forma, é possível analisar manifestações patológicas resultantes do ataque do sulfato de sódio e do ácido sulfúrico, assim como analisar a diferença de comportamento de cada tipo de cimento quando exposto a estes elementos. Todas as barras foram fotografadas em todas as idades.

\subsubsection{Ensaio de determinação da variação de massa}

Os ensaios de alteração de massa são comuns em experimentos que utilizam ataque ácido, mas os mesmos dependem do tipo de cimento e do tamanho da amostra, que pode ser influenciada pelas reações de expansão que ocorrem quando a estrutura começa a ser degradada. As ações combinadas de dissolução e expansão causa gradualmente a falha na camada superficial de argamassa de cimento, o que provoca a redução da massa significativa (CHANG et al., 2005)

Girardi, Vaona e Di Maggio (2010) realizaram um ensaio no qual verificaram a perda de massa e expansão de corpos de prova de concreto, submetidos ao ataque cíclico de sulfato de sódio e ácido sulfúrico, com variações no tipo de cimento e nas adições. Com os resultados, verificou-se que nas amostras que apresentaram menor expansão, a taxa de perda de massa foi maior, logo, ambos os fatores devem ser considerados no projeto e no estudo de estruturas.

Apesar do procedimento descrito por Girardi, Vaona e Di Maggio (2010), no qual os corpos de prova são pesados antes da imersão e ao final do ensaio. Neste experimento, os corpos de prova foram pesados anteriormente ao ensaio e em cada medição de expansão realizada para verificar a variação de massa. 


\section{RESULTADOS E DISCUSSÕES}

\subsection{CARACTERIZAÇÃO DOS MATERIAIS}

A seguir apresenta-se os dados de caracterização dos materiais empregados no experimento.

\subsubsection{Cimento}

A partir da Tabela 4 é possível anunciar que os cimentos utilizados foram o Cimento Portland (CP) II Z 32, CP IV RS e CP V ARI, cujas composições químicas, físicas e mecânicas são informadas na especificação do fabricante.

\subsubsection{Agregado miúdo}

O agregado miúdo apresentou resultados adequados ao ensaio, uma vez que a zona granulométrica da areia utilizada foi zona ótima e na norma especifica que a areia utilizada deve ser areia média. De acordo com os resultados obtidos foi verificado que o módulo de finura da areia utilizada é 2,63 e está de acordo com a especificação para areia do tipo média. Os resultados da caracterização da areia estão apresentados na Tabela 5.

A Figura 2 apresenta os resultados referentes à distribuição granulométrica do agregado miúdo em ensaio realizado a partir de norma técnica referenciada na Tabela 5.

TABELA 4: Caracterização do cimento CP II Z, CP IV e CP V ARI.

\begin{tabular}{cccc} 
Componente & \multicolumn{3}{c}{ Tipo de cimento } \\
\cline { 2 - 4 } & $\mathrm{CP} \mathrm{II} \mathrm{Z}$ & CP IV RS & CP V \\
\hline $\mathrm{Al}_{2} \mathrm{O}_{3}(\%)$ & - & 9,76 & 4,41 \\
\hline $\mathrm{SiO}_{2}(\%)$ & - & 29,07 & 18,9 \\
\hline $\mathrm{Fe}_{2} \mathrm{O}_{3}(\%)$ & - & 3,85 & 2,70 \\
\hline $\mathrm{CaO}(\%)$ & 54,67 & 45,12 & 60,55 \\
\hline $\mathrm{MgO}(\%)$ & 5,53 & 2,92 & 4,49 \\
\hline $\mathrm{SO}_{3}(\%)$ & 2,98 & 2,25 & 2,59 \\
\hline Perda ao fogo (\%) & - & - & 3,1 \\
\hline Resíduo insolúvel (\%) & 12,52 & 25,44 & 0,83 \\
\hline Equivalente alcalino (\%) & 0,86 & 1,14 & 0,65 \\
\hline Expansibilidade a quente (\%) & 0,58 & 0,30 & 0,17 \\
\hline Tempo de Pega (Início) & $4: 47$ & $04: 29$ & $3: 16$ \\
\hline Tempo de Pega (Fim) & $5: 59$ & $5: 15$ & $3: 53$ \\
\hline Consistência normal (\%) & 27,7 & 29,9 & 28,9 \\
\hline Blaine (cm²/g) & 3553 & 4171 & 3978 \\
\hline \#200 (\%) & 1,62 & 0,46 & 0,14 \\
\hline \#325 (\%) & 11,04 & 2,71 & 01,78 \\
\hline dias & 37,23 & 45,3 & 51,9 \\
\hline Resistência à compressão (MPa) aos 28 & 2,98 & 2,82 & 3,09 \\
\hline Massa específica (g/cm ${ }^{2}$ ) & Votorantim & Itambé & Itambé \\
\hline Fabricante & $16 / 05 / 2016$ & $08 / 06 / 2016$ & $03 / 05 / 2016$ \\
\hline Lote & & & \\
\hline
\end{tabular}


TABELA 5: Caracterização do agregado miúdo.

\begin{tabular}{ccc} 
Parâmetros & Resultado & Norma Referência \\
\hline \multirow{2}{*}{ Massa especifica $\left(\mathrm{g} / \mathrm{cm}^{3}\right)$} & $\begin{array}{c}\mathrm{E} 1=2,595 \\
\mathrm{E} 2=2,595\end{array}$ & NBR NM 52 (ABNT, 2003) \\
\hline Massa unitária $\left(\mathrm{g} / \mathrm{cm}^{3}\right)$ & $\begin{array}{c}\mathrm{E} 1=1,612 ; \\
\mathrm{E} 2=1,605\end{array}$ & NBR 7251 (ABNT, 1982) \\
\hline Módulo de finura & 2,63 & NBR NM 248 (ABNT, 2003) \\
\hline Teor de material pulverulento (\%) & $\mathrm{E} 1=2,53 ;$ & NBR NM 46 (ABNT, 2003) \\
\hline Composição granulométrica & Zona ótima (Figura 2) & NBR NM 248 (ABNT, 2003) \\
\hline
\end{tabular}

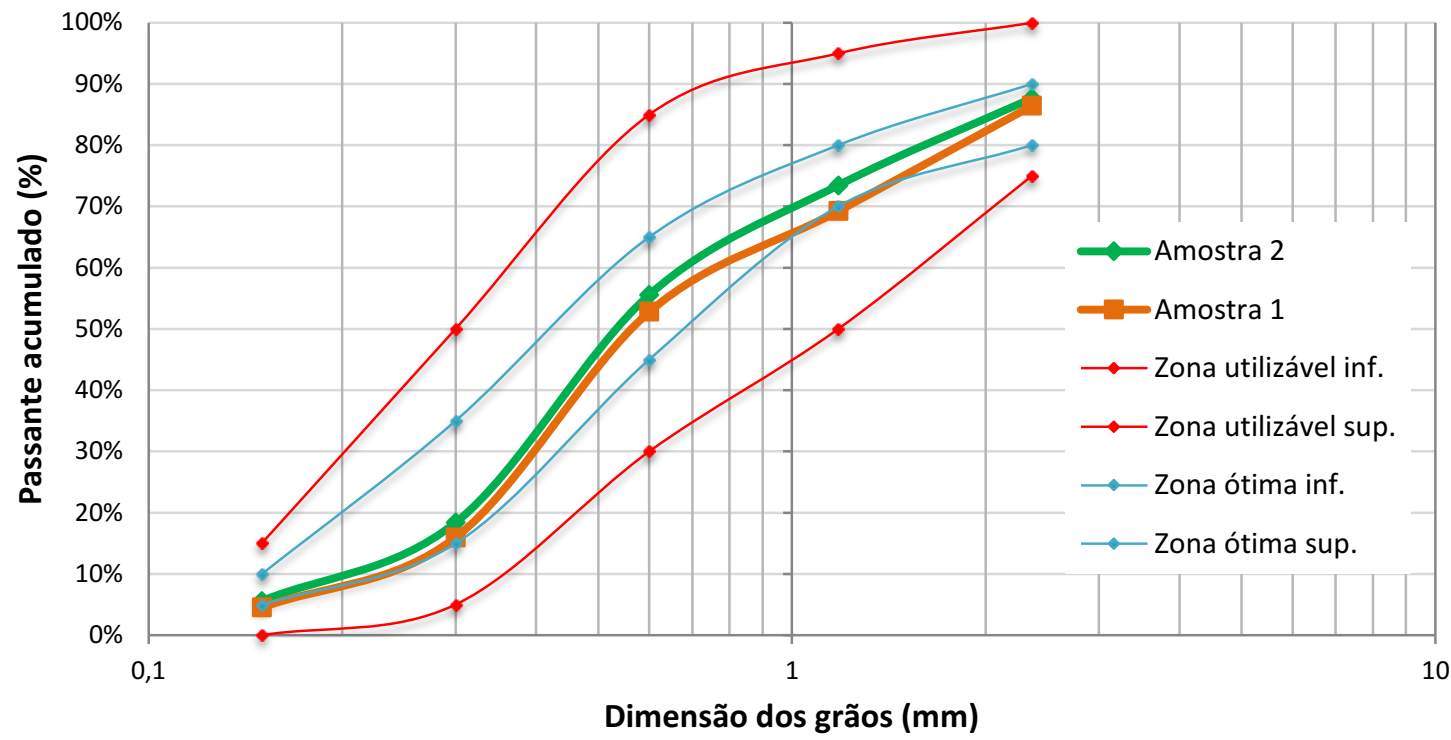

FIGURA 2: Curva granulométrica do agregado miúdo (areia natural) utilizado.

FONTE: Autoria própria.

\subsection{ANÁLISE DA VARIAÇÃO DIMENSIONAL}

Após a cura dos corpos de prova, foi realizada a medida inicial dos mesmos em um relógio comparador. A NBR 13583 (ABNT, 2014) especifica que seja realizada as medições nas datas de 14, 28 e 42 dias, porém, não foi possível realizar as medidas aos 42 dias e foi necessário realizá-las aos 51 dias.

Com as medidas realizadas foi obtida a expansão média dos corpos de prova. Para os corpos de prova de cimento $C P V$ e cimento $C P \| Z$, a média foi realizada com os valores de seis corpos de prova. No caso do cimento CP IV-32 RS, a média foi realizada com os valores de cinco corpos de prova de argamassa.

De acordo com a NBR 13583 (ABNT, 2014), para expansões resultantes menores do que $0,02 \%$ o valor da expansão é desconsiderado no cálculo da média quando difere em até $0,03 \%$. No entanto, para expansões maiores do que $0,02 \%$, se o valor diferir em até $15 \%$ da média, o mesmo deve ser desconsiderado para o cálculo da média e deverá ser realizado o cálculo de uma nova média sem esse valor.

Para obter a expansão resultante é feito um cálculo do valor de expansão na solução agressiva (Es), seja ela de sulfato de sódio ou de ácido sulfúrico em relação à expansão de água saturada com cal (Ea). Com esses valores foi possível verificar a expansão resultante (Ae) dos corpos de prova conforme a Equação 1.

$$
\mathrm{Ae}=\mathrm{Es}-\mathrm{Ea} \quad(\%)
$$

Em que:

$\mathrm{Ae}=$ valor da expansão resultante (\%);

$\mathrm{Es}=$ valor da expansão agressiva (\%);

$\mathrm{Ea}=$ valor da expansão de água santurada com cal (\%). 
Os valores de expansão resultante para este ensaio estão apresentados na Tabela 6.

Pode-se observar na Tabela 6 que a variação da retração/expansão para o cimento $\mathrm{CP}$ IV-32 RS foi menor do que para os demais cimentos, quando expostos a solução de ácido sulfúrico, uma vez que o valor de expansão aos 7 dias foi 0,125 e o de expansão aos 44 dias foi de 0,308, logo, a variação dimensional entre um período e outro foi de aproximadamente 0,183.

Para os corpos de prova de argamassa de cimento $C P V$, a variação dimensional resultante obtida aos 7 dias foi $-0,407$ e a variação dimensional aos 51 dias foi de 0,922. Logo, a variação no período foi de 1,32.

Os corpos de prova expostos à solução de ácido sulfúrico que tiveram maior variação dimensional foram os corpos de prova de cimento CP II Z, que apresentaram expansão resultante de 0,127 aos 7 dias, expansão resultante aos 1,259 aos 51 dias, sendo que a variação no período foi de 1,132 .

Na Figura 3 é apresentada a variação dimensional dos corpos de prova estudados.

TABELA 6: Expansão resultante dos corpos de prova de argamassa com diferentes tipos de cimento.

Expansão Resultante (\%)

\begin{tabular}{cccccccc}
\hline & \multicolumn{1}{c}{ Solução } & $\mathbf{7}$ dias & $\mathbf{1 4}$ dias & $\mathbf{2 1}$ dias & $\mathbf{2 8}$ dias & $\mathbf{4 4}$ dias & $\mathbf{5 1}$ dias \\
\hline \multirow{2}{*}{ Cimento CP V } & Sulfato de sódio & - & 0,003 & - & $-0,018$ & - & 0,012 \\
\cline { 2 - 7 } & Ácido sulfúrico & $-0,407$ & $-0,012$ & $-0,023$ & $-0,078$ & 0,922 & - \\
\hline \multirow{2}{*}{ CP IV-32 RS } & Sulfato de sódio & - & 0,013 & - & 0,049 & - & 0,037 \\
\cline { 2 - 8 } & Ácido sulfúrico & 0,125 & 0,352 & 0,363 & 0,283 & 0,308 & - \\
\hline \multirow{2}{*}{ Cimento CP II Z } & Sulfato de sódio & - & 0,001 & - & 0,006 & - & 0,209 \\
\cline { 2 - 7 } & Ácido sulfúrico & 0,127 & $-0,392$ & 0,280 & 1,175 & 1,259 & - \\
\hline
\end{tabular}

FONTE: Autoria própria. 


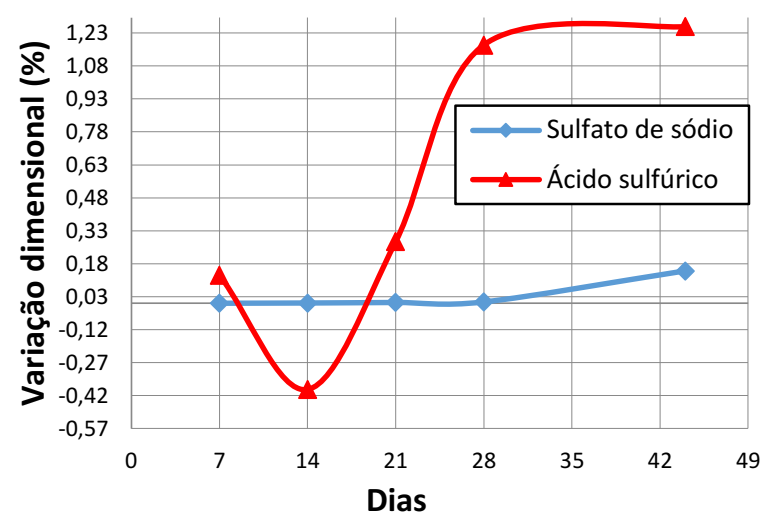

[a]

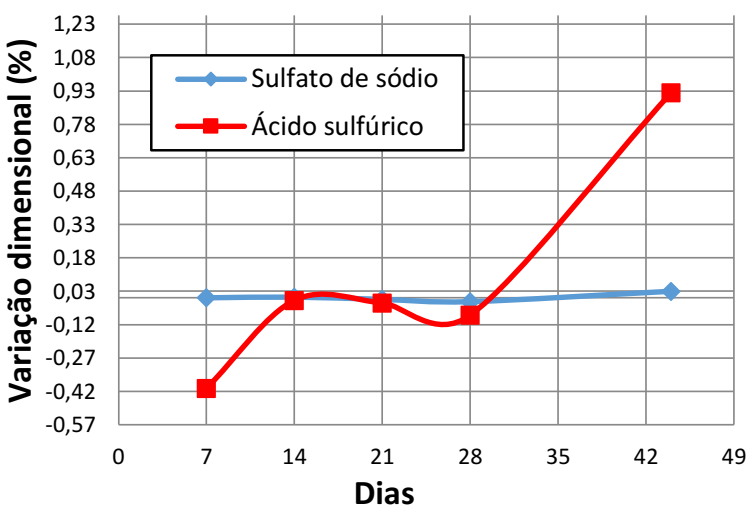

[b]

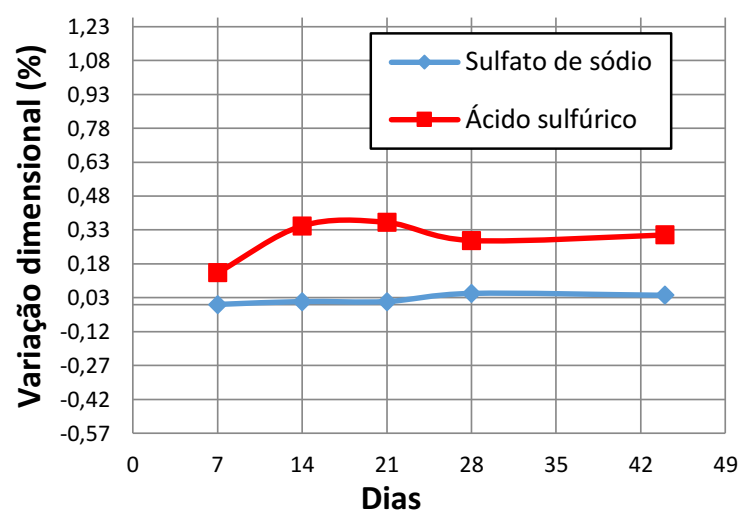

[c]

FIGURA 3: Variação dimensional dos corpos de prova, sendo [a] corpos de prova de CPII Z,

[b] corpos de prova de CP V e [c] corpos de prova de CP IV RS.

FONTE: Autoria própria.

Na Figura 3 [a], pode-se observar que os corpos de prova de argamassa imersos na solução de ácido sulfúrico tiveram maior variação dimensional do que os corpos de prova de argamassa expostos à solução de sulfato de sódio para todos os casos, o que já era esperado pelo fato de ser uma solução mais agressiva.

$A$ variação dimensional para o CP II Z em relação do CP IV-32 RS foi sete vezes maior e em contrapartida, a variação dimensional para o cimento CP $\vee$ foi de aproximadamente cinco vezes maior do que a variação dimensional do CP IV-32 RS.

\subsection{VARIAÇÃO DE MASSA DOS CORPOS DE PROVA}

A avaliação da variação de massa foi realizada para verificar a se os corpos de CP II Z tiveram maior ou menor perda de massa com a expansão.
Na Figura 4 é apresentada a variação da massa dos corpos de prova.

Verificou-se que nas amostras atacadas por ácido sulfúrico o $\mathrm{pH}$ da solução apresentou maior variação, o que indicaria que os compostos do cimento estariam sendo dissolvidos pela solução. Outro fenômeno que pode ocorrer é o ganho de massa, pela formação de compostos expansivos ou preenchimento dos poros da argamassa o com solução.

Na Figura 4 observa-se o aumento da massa dos corpos de prova, no entanto, não é possível concluir se esse aumento de massa ocorreu devido ao preenchimento dos poros pela solução ou pela formação de produtos expansivos como por exemplo a etringita $\mathrm{C}_{6} \mathrm{ASH}_{32}$.

As reduções de massa observadas podem ser devido a dissolução dos produtos da argamassa nas soluções na qual estavam expostas. 


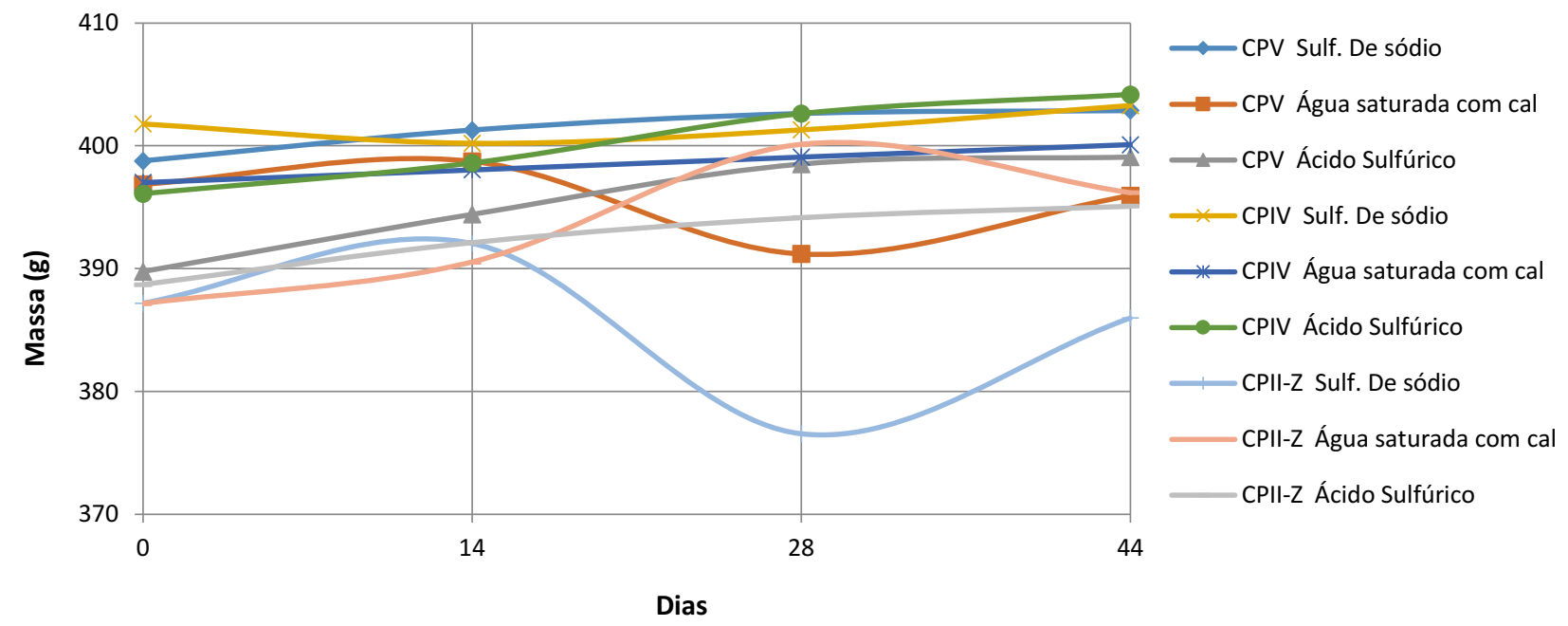

FIGURA 4: Variação da massa dos corpos de prova expostos a soluções agressivas de sulfatos. FONTE: Autoria própria.

\subsection{VARIAÇÃO DO pH DAS SOLUÇÕES}

Com a imersão dos corpos de prova nas soluções, alguns compósitos de cimento são dissolvidos e ocorre a dissolução dos mesmos na solução. A dissolução dos compostos do cimento,

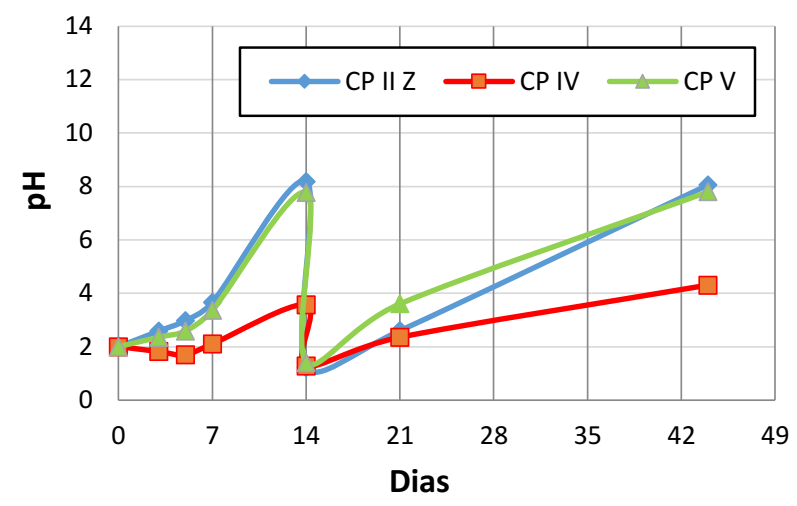

[a] ocorre ainda a alteração do valor de $\mathrm{pH}$ da solução. Este fato pode ser observado na Figura 5, no qual mostra o aumento da alcalinidade da solução de ácido sulfúrico devido à possível dissolução de compostos básicos de cimento.

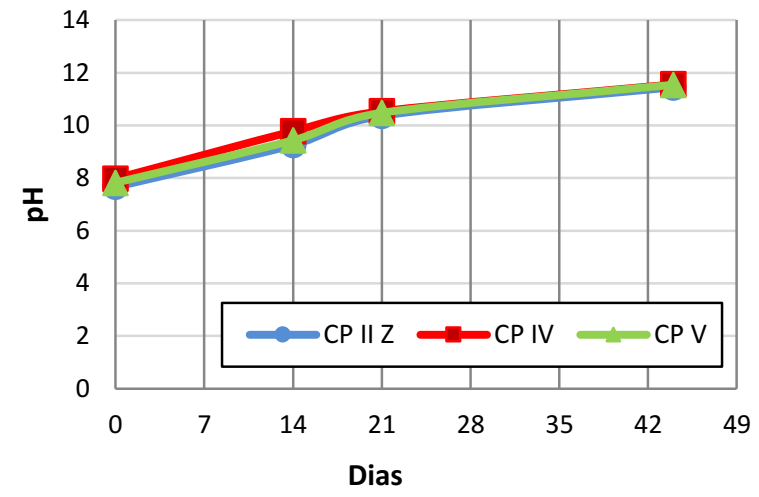

[b]

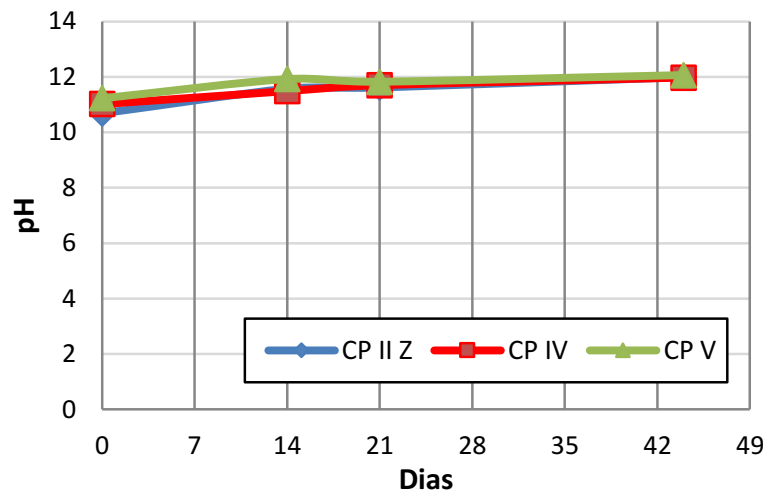

[c]

FIGURA 5: Variação do pH das soluções, sendo [a] com ácido sulfúrico, [b] com solução de sulfato de sódio e [c] com água saturada com cal.

FONTE: Autoria própria. 
Como as soluções de ácido sulfúrico foram as que tiveram maior alteração, mesmo que os corpos de prova tenham sido expostos a pouco tempo de exposição, foi realizada a correção do $\mathrm{pH}$ das mesmas. Na solução de ácido sulfúrico após 14 dias de imersão dos corpos de prova de cimento CP IV-32 RS, houve a precipitação de sólidos, possivelmente pela decomposição dos compósitos de cimento.

$\mathrm{Na}$ solução de sulfato de sódio e na solução de água saturada com cal houve pouca variação no $\mathrm{pH}$ e estas variações foram gradativas e sem descontinuidade, mostrando assim que os processos de dissolução química da argamassa nestes meios são mais lentos do que na solução com ácido sulfúrico.

Além disso, não houve variação visível na cor da solução de água saturada com cal e de sulfato de sódio como ocorreu com a solução de ácido sulfúrico.

Dessa maneira, é possível verificar que a solução de ácido sulfúrico $1 \%$ está reduzindo a alcalinidade dos corpos de prova de argamassa, enquanto as soluções de sulfato de sódio e de água saturada com cal tiveram uma redução da alcalinidade dos corpos de prova de argamassa menor do que a amostra imersa em ácido sulfúrico.

\section{CONSIDERAÇÕES FINAIS}

Os corpos de prova moldados com cimento de maior teor de adição (CP IV-32 RS) tiveram a menor variação dimensional frente aos ataques submetidos, sulfato de sódio e ácido sulfúrico.

Os diferentes tipos de cimento utilizados resultaram em valores diferentes de variação dimensional frente ao ataque de ácido sulfúrico. Com relação aos corpos de prova imersos em solução de hidróxido de sódio, os valores máximos de variação dimensional observados no período da realização dos ensaios foram de: CP V - 0,93\%, CP IV-32 RS- 0,349\% e CP II-Z - 1,003\%, ficando os valores do CP IV-32 RS cerca de um terço dos demais.
Quanto ao ensaio de perda de massa, foi verificado que os corpos de prova imersos em solução de ácido sulfúrico tiveram um ganho de massa de $2 \%$ em relação ao início do ensaio, enquanto os corpos de prova imersos em solução de sulfato de sódio e água saturada com cal tiveram ganho de massa inicial de $1 \%$. Verifica-se ainda que não ocorreu perda de massa significativa no ensaio para os corpos de prova imersos em ácido sulfúrico.

Nos corpos de prova imersos em solução de ácido sulfúrico é possível observação a alteração na porosidade e coloração dos corpos de prova de argamassa com apenas 7 dias em imersão. As faces dos corpos de prova que estavam anteriormente lisas, após o ataque por ácido sulfúrico se apresentam ásperas.

Os corpos de prova imersos em soluções de sulfato de sódio e água saturada com cal não apresentaram degradação tão avançada quanto os corpos de prova imersos no ácido sulfúrico, mesmo após terem ficado mais tempo expostos às soluções agressivas.

Contudo, a utilização da NBR 13583 (ABNT, 2014) para avaliar o cimento a ser utilizado em ambientes com a presença de ácido sulfúrico, como indústrias, estações de tratamento de esgoto e outros não é o mais adequado, pois a norma especifica que os referidos cimentos que seriam resistentes ao sulfato de sódio não é resistente ao ácido sulfúrico, por exemplo, pois o sulfato de sódio não é tão agressivo quanto o ácido sulfúrico. Dessa maneira, o cimento que não irá sofrer variação dimensional com sulfato de sódio, pode ter uma variação acentuada com o ácido sulfúrico.

Deste modo, é necessário especificar materiais mais resistentes para locais que estejam sujeitos ao ataque por ácido sulfúrico, sejam eles para diferentes tipos de argamassas, de concretos ou para outros tipos de materiais utilizados para a impermeabilização das estruturas. Além disso, a utilização de impermeabilização com materiais cimentícios para este ambiente não seria adequada, uma vez que o cimento perde as propriedades que garantem a durabilidade da 
estrutura nestes ambientes.

\section{AGRADECIMENTOS}

Os autores expressam a sua gratidão a Universidade Federal do Paraná (UFPR), ao Instituto IDD, ao Programa de Pós-Graduação em Engenharia de Construção Civil (PPGECC), ao Centro de Estudos de Engenharia Civil (CESEC), ao Laboratório de Materiais e Estruturas (LAME-DCC) e ao grupo de pesquisa de Patologia e Recuperação das Construções da UFPR coordenado pelo professor Dr. Marcelo Henrique Farias de Medeiros.

\section{REFERÊNCIAS BIBLIOGRÁFICAS}

ASSOCIAÇÃO BRASILEIRA DE NORMAS TÉCNICAS NBR 7251: Agregado em estado solto - determinação da massa unitária. Rio de Janeiro, Brasil, 1982.

NBR 5737: Cimentos Portland resistentes a sulfatos. Associação Brasileira de Normas Técnicas ABNT, Rio de Janeiro, Brasil, 1992.

NBR NM 248: Agregado em estado solto determinação da massa unitária. Rio de Janeiro, Brasil, 2003.

NBR NM 46: Agregados - Determinação do material fino que passa através da peneira $75 \mathrm{um}$, por lavagem. Rio de Janeiro, Brasil, 2003.

NBR NM 52: Agregado graúdo Determinação de massa específica, massa específica aparente e absorção de água. Rio de Janeiro, Brasil, 2003.

NBR 7211: Agregados para concreto especificação. Rio de Janeiro, Brasil, 2009.

NBR 13583: Cimento Portland Determinação da variação dimensional de barras de argamassa de cimento Portland expostas à soluções de sulfato de sódio. ABNT, Rio de Janeiro, Brasil, 2014.

NBR 6118: Projeto de Estruturas de Concreto - Procedimento. Associação Brasileira de Normas Técnicas. ABNT, Rio de Janeiro, Brasil, 2014.

CHANG, Z. T.; SONG, X. J.; MUNN, R..; MAROSSZEKY, M. Using limestone aggregates and different cements for enhancing resistance of concrete to sulphuric acid attack. Cement and Concrete Research. 35. 1486-1494, 2005.
GIRARDI, F. VAONA, W. DI MAGGIO, R. Resistance of different types of concretes to cyclic sulfuric acid and sodium sulfate attack. Cement and Concrete Composites. v.32, n.8, p.595-602, 2010.

GRENGG, C.; MITTERMAYR, F.; BALDERMANN, A.; BOTTCHER, M.E.; LEIS, A.; KORAIMANN, G.; GRUNERT, P.; DIETZEL, M. Microbiologically induced concrete corrosion: A case study from a combined sewer network. Cement and Concrete Research, v. 77, p. 1625, 2015.

HOPPE FILHO, J., RHEINHEIMER, B.; KHOE, S. S.; ARTIGAS, L. V.; SABBAG, A. F.; MEDEIROS, M. H. F. Degradação do concreto de uma estação de tratamento de Esgoto (ETE) por ácido sulfúrico biogênico. Revista ALCONPAT, v. 4, n. 2, p. 87-99, Maio - Agosto 2014.

JIANG, G.; SUN, X.; KELLER, J.; BOND, P. L. Identification of controlling factors for the initiation of corrosion of fresh concrete sewers. Water Research, 80, 30-40. 2015.

JOSEPH, A. P.; KELLER, J.; BUSTAMANTE, H.; BOND, P. L. Surface neutralization and $\mathrm{H} 2 \mathrm{~S}$ oxidation at early stages of sewer corrosion: influence of temperature, relative himidity and $\mathbf{H} 2 \mathrm{~S}$ concentration. Water Research, p. 4235-4245, 2012.

MEHTA, P. K.; MONTEIRO, P. J. Concreto: microestrutura, propriedades e materiais. 2a edição Brasileira. 4ạ Edição em inglês. São Paulo. Brasil, 2014.

OKABE, S.; ODAGIRI, M.; ITO, T.; SATO, H. Succession of Sulfur-Oxidizing Bacteria in the Microbial Community on Corroding Concrete in Sewer Systems. Applied and Environmental Microbiology, p. 971-980, february 2007.

TORII, K.; KAWAMURA, M. Effects of Fly Ash and Silica Fume on the Resistance. Cement and Concrete Research, v. 24, n. 2, p. 361-370, 1994.

WELLS, T.; MELCHERS, R. E. An observation-based model for corrosion of concrete sewers under aggressive conditions. Cement and Concrete Research, v. 61, p. 1-10, 2014. 